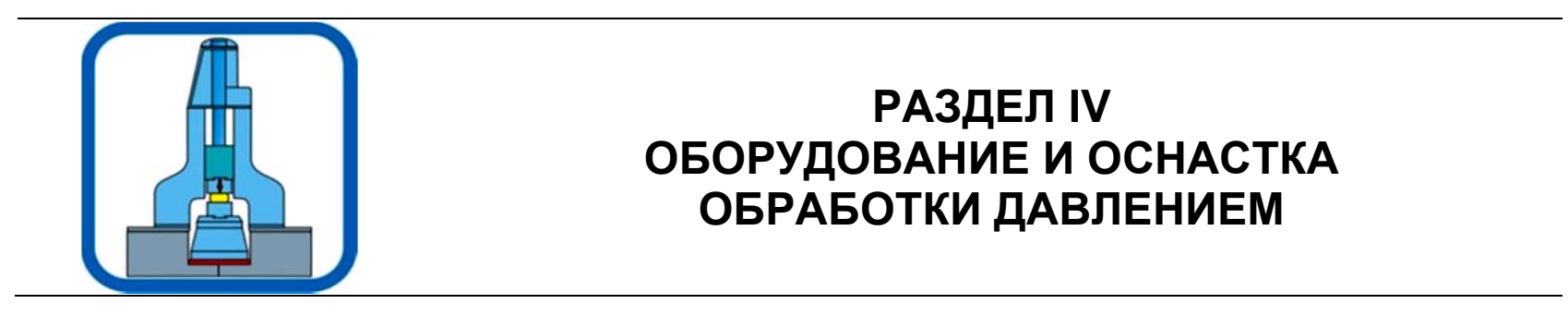

УДК 621.967 .1

Боровик П. В.

\title{
ОБОСНОВАНИЕ ПРОФИЛИРОВКИ ФАСОННОГО НОЖА ДЛЯ РАЗДЕЛЕНИЯ КВАДРАТНОЙ ЗАГОТОВКИ В ГОРЯЧЕМ СОСТОЯНИИ
}

Неотъемлемой составляющей технологий прокатного производства являются разделительные операции металлопроката. Процессы разделения, как известно из практики прокатки, способны оказывать существенное влияние не только на качество готового металлопроката, но и на эффективность реализации последующих технологических операций. В современных условиях решение данного типа задач возможно при условии повышения точности производимых конструкторских расчетов и увеличения степени научной обоснованности при принятии проектных и технологических решений.

В практике металлургического производства в различных технологических схемах производства сортового металлопроката широко применяют операции поперечного разделения на ножницах $[1,2]$. При этом повышение требований к качеству готового металлопроката и стремление расширить технологические возможности ножниц способствуют повышению интереса в данной области $[3,4]$.

К основным преимуществам процесса разделения металла на ножницах следует отнести: безотходность и высокую (по сравнению с газовой резкой) скорость резки, а также высокую точность и качество реза. Это, в свою очередь, способствует расширению возможных технологических схем, в которых производители металлургических машин отдают предпочтение именно ножницам. Так один из крупнейших в Украине и мире заводов тяжёлого машиностроения ПАО «Новокраматорский машиностроительный завод» предлагает на машинах непрерывного литья сортовых заготовок (МНЛЗ), процесс поперечной резки заготовки на мерные длины, осуществлять при помощи летучих гидравлических ножниц оригинальной конструкции (рис. 1). С учетом специфики разработанных сортовых МНЛ3, имеющих разливаемое сечение от $100 \times 100$ до $150 \times 150$ мм, данный процесс реализуют на ножницах поперечной резки с ножами соответствующей треугольной формы и траекторией их взаимного перемещения, наклоненной под углом $45^{\circ}$ к горизонтальной плоскости.

Данная конструкция ножниц позволяет разрезать заготовки с максимальным сечением $150 \times 150$ мм при температуре не ниже $800{ }^{\circ} \mathrm{C}$ со скоростью до 70 мм/с и максимальной силой резки 2,4 МН.

Отличительной особенностью ножей в ножницах данной конструкции является тот факт, что угол раскрытия ножей треугольной формы ( см. рис. 1, б) составляет $\alpha=94^{\circ}$, а уклон контактных поверхностей $-\beta=7^{\circ}$. Это позволяет снизить силу резки и повысить качество реза.

При этом качество разделения должно удовлетворять основным требованиям, предъявляемым к сортовому прокату, в частности [5]: обеспечение заданной точности по длине; формирование прямого среза; минимизация смятия концов заготовки и явления заусенцев. 
Точность поперечной резки сортового проката и допустимая величина косины реза, а также методы контроля отклонения формы металлопродукции (в некоторых странах бывшего СССР, в том числе и в Украине), регламентируются рядом нормативных документов [5-8].

Качество резки сортовой заготовки характеризуется такими дефектами как заусенцы (или завал кромки) и смятие (утяжку) концов раската [9]. Очевидно, что при рациональной профилировке ножей можно добиться удовлетворения требований к качеству резки, снизить показатели брака и повысить выход годного металлопроката.

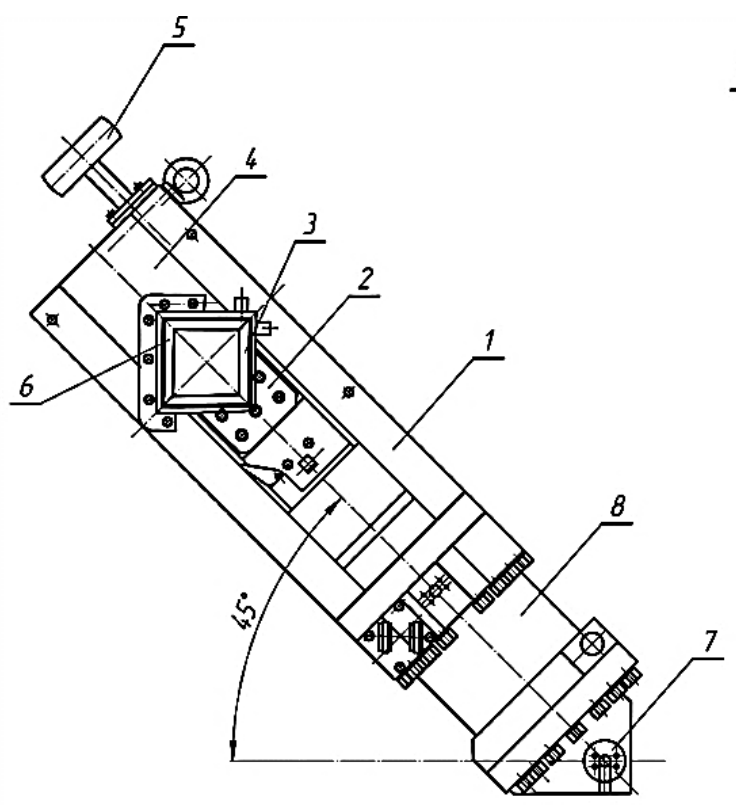

a

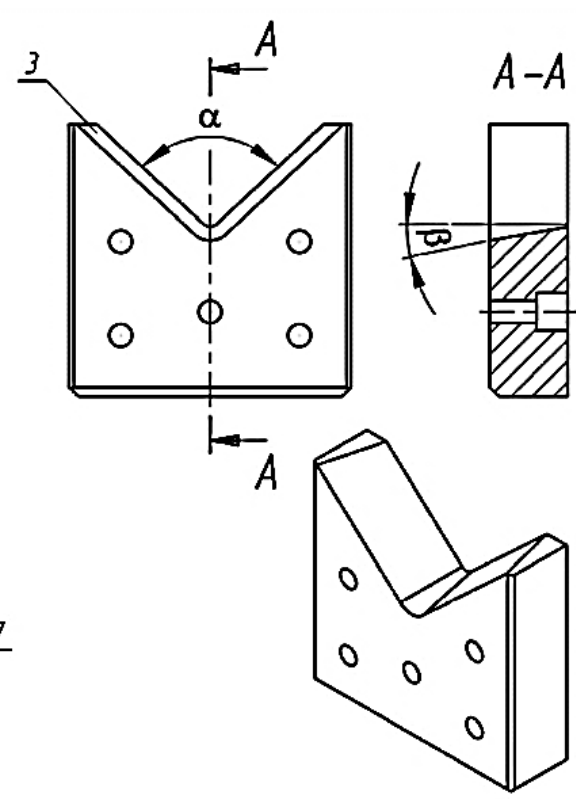

6

Рис. 1. Общий вид (а) ножниц летучих гидравлических конструкции НКМЗ для поперечной горячей резки на мерные длины непрерывно-литых квадратных заготовок и профилировка ножа (б):

1 - станина; 2, 4 - нижний и верхний суппорт; 3, 6 - фасонные ножи; 5 - верхний ролик; 7 - цилиндрическая направляющая; 8 - гидроцилиндр

Кроме того, учитывая, что квадратная заготовка на данных ножницах режется по диагонали, еще одним показателем качества реза является ромбичность в сечении среза, которая проявляется в виде искажения геометрической формы поперечного сечения и отклоняется от исходной квадратной за счет разности диагоналей. Величина ромбичности имеет существенное значение для последующей прокатки заготовок, поскольку от этого зависит их самоустанавливание в калибре.

Безусловно, что для определения рациональной профилировки ножа необходимы экспериментальные исследования, однако такой подход связан с целым рядом организационных и финансовых трудностей. Учитывая возможности современной вычислительной техники, а также развитие методов математического моделирования, целесообразно смещать акценты на новые подходы в исследовании различных технологических процессов обработки металлов давлением (ОМД) [10], что, в первую очередь, относится к методу конечных элементов (МКЭ). Применение МКЭ позволяет значительно расширить представление о протекании процессов и повысить степень научной обоснованности при принятии технологических и конструктивных решений. Так в работе [11] представлена трехмерная математическая модель процесса поперечного разделения на ножницах непрерывнолитых сортовых заготовок в горячем состоянии, позволяющая адекватно отображать энергосиловые и геометрические параметры процесса и наиболее полно учесть геометрические особенности режущего инструмента. 
Цель данной работы заключалась в теоретическом обосновании профилировки фасонного ножа для разделения квадратной заготовки в горячем состоянии путем математического моделирования на базе метода конечных элементов.

Для достижения указанной цели использовали трехмерную математическую модель процесса поперечного разделения на ножницах непрерывнолитых сортовых заготовок в горячем состоянии, представленную в работе [11].

Данная математическая модель (рис. 2, а) была разработана на базе конечноэлементного программного комплекса Abaqus [12] и состоит из двух абсолютно жестких недеформируемых тел - верхний и нижний фигурный ножи, а также деформируемого бруса, моделирующего разделяемую заготовку квадратного сечения.
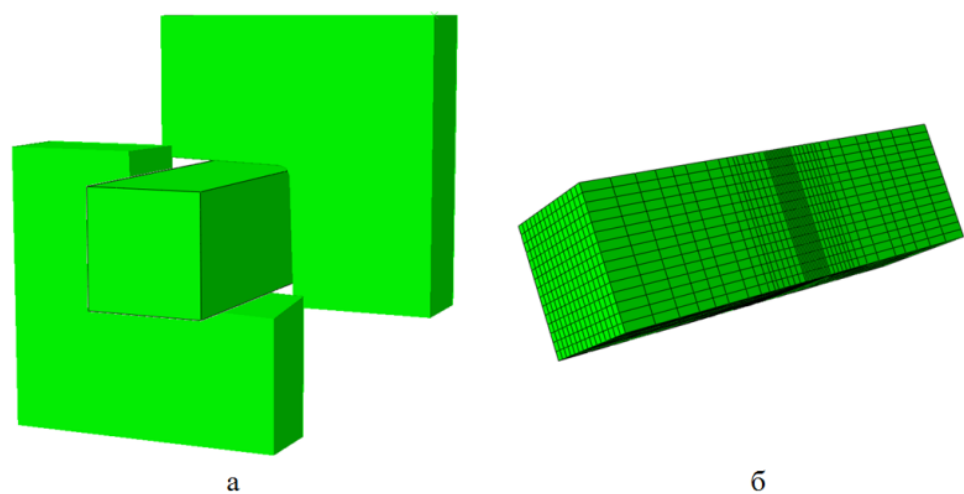

Рис. 2. Общий вид модели (а) и заготовки с нанесенной сеткой (б) [11]

При этом по аналогии с реальной конструкцией ножниц движение сообщается нижнему ножу, тогда как верхний нож остается неподвижным.

Деформируемый брус представляет собой сетку (см. рис. 2, б) из изопараметрических шестигранных восьмиузловых линейных элементов с редуцированной схемой интегрирования, имеющих свойства сплошной деформируемой среды, а сетка имеет сгущение в очаге резки.

Учитывая, что процесс резки сопровождается большими пластическими деформациями, в ходе математического моделирования использовалась процедура адаптации внутренней сетки в формулировке Лагранжа-Эйлера $[10,12]$, тогда как поведение узлов на поверхности заготовки описывалось формулировкой Лагранжа. Инструменты моделировались как дискретные недеформируемые поверхности.

В основу модели контактного взаимодействия между заготовкой и инструментами положен закон трения Амонтона-Кулона.

На торцевые поверхности бруса накладывалось ограничение по их перемещению вдоль продольной оси бруса, что близко к условиям разделения длинномерных непрерывнолитых заготовок.

Разрушение материала моделировалось методом исключения элементов из расчета, после исчерпания ресурса пластичности в соответствии с диаграммой пластичности [10].

При построении кривых текучести материала использовали методику [13], позволяющую учитывать влияние температуры, степени и скорости деформации, а также химического состава материала заготовки на сопротивление деформации.

Для оценки влияния профилировки ножей на формообразование заготовки в зоне реза были выполнены симуляции процесса с ножами различной конфигурации. В частности, угол в вершине ножей принимали равным $\alpha=86 ; 90 ; 94$ и 98, а уклон контактных поверхностей $\beta=0 ; 3,5 ; 7$ и $10,5^{\circ}$.

Симуляция процесса производилась для условий резки заготовки сечением $120 \times 120$ мм из стали 20 при температуре $970{ }^{\circ} \mathrm{C}$ со скоростью $70 \mathrm{Mm} / \mathrm{c}$, что соответствовало производственным данным. 
В результате были получены профили формы торцевой поверхности заготовки после порезки, которые подтверждают, что формообразование торцевой поверхности существенно зависит от конфигурации ножа.

При обработке полученных результатов моделирования производились замеры геометрических параметров торцевой поверхности после порезки по схеме, представленной на рис. 3. Результаты замеров соответствующих параметров приведены в табл. 1.

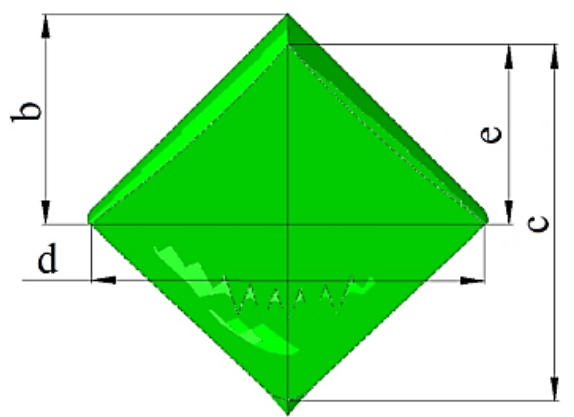

Рис. 3. Схема замеров геометрических параметров торцевой поверхности заготовки после порезки на ножницах

Таблица 1

Результаты замеров геометрических параметров по схеме на рис. 3

\begin{tabular}{|c|c|c|c|c|c|c|}
\hline № & $\alpha$ & $\beta$ & $\mathrm{b}$ & $\mathrm{d}$ & $\mathrm{c}$ & $\mathrm{e}$ \\
\hline 1 & \multirow{4}{*}{86} & 0 & 83,34 & 159,87 & 155,08 & 70,36 \\
\hline 2 & & 3,5 & 80,8 & 159,24 & 153,41 & 69,22 \\
\hline 3 & & 7 & 78,03 & 158,25 & 150,28 & 66,21 \\
\hline 4 & & 10,5 & 75,66 & 157,85 & 147,78 & 64,46 \\
\hline 5 & \multirow{4}{*}{90} & 0 & 86,01 & 160,38 & 154,04 & 74,87 \\
\hline 6 & & 3,5 & 84,06 & 159,66 & 150,69 & 72,08 \\
\hline 7 & & 7 & 81,81 & 159,02 & 148,39 & 69,93 \\
\hline 8 & & 10,5 & 79,40 & 158,47 & 146,14 & 67,52 \\
\hline 9 & \multirow{4}{*}{94} & 0 & 88,68 & 160,88 & 150,20 & 75,90 \\
\hline 10 & & 3,5 & 87,04 & 160,56 & 148,24 & 74,07 \\
\hline 11 & & 7 & 84,96 & 160,63 & 146,77 & 72,63 \\
\hline 12 & & 10,5 & 83,15 & 159,10 & 144,50 & 70,58 \\
\hline 13 & \multirow{4}{*}{98} & 0 & 93,68 & 164,09 & 150,14 & 79,02 \\
\hline 14 & & 3,5 & 91,39 & 162,26 & 146,92 & 76,72 \\
\hline 15 & & 7 & 89,06 & 160,64 & 145,44 & 75,42 \\
\hline 16 & & 10,5 & 86,89 & 159,73 & 142,86 & 73,64 \\
\hline
\end{tabular}

В ходе обработки данных моделирования были получены три относительных параметра, два из которых характеризуют смятие (утяжку) концов раската $k_{b}$ и $k_{e}$, и еще один ромбичность $k_{d}$ торцевой поверхности:

$$
k_{b}=\frac{b}{\sqrt{2} h} ; \quad k_{e}=\frac{e}{c} ; \quad k_{d}=\frac{d}{c}
$$

где $\sqrt{2} h$ - исходная диагональ квадратной заготовки со стороной $h$.

Затем, используя метод наименьших квадратов [14], были получены уравнения регрессии параметров, в функции углов $\alpha$ и $\beta$ : 


$$
\begin{aligned}
& k_{b}=6,27 \cdot 10^{-2}+4,95 \cdot 10^{-3} \cdot \alpha-8,69 \cdot 10^{-3} \cdot \beta+5,36 \cdot 10^{-5} \cdot \alpha \cdot \beta \\
& k_{e}=-4,18 \cdot 10^{-2}+5,81 \cdot 10^{-3} \cdot \alpha-8,55 \cdot 10^{-3} \cdot \beta+7,48 \cdot 10^{-5} \cdot \alpha \cdot \beta \\
& k_{d}=0,542+5,62 \cdot 10^{-3} \cdot \alpha+1,59 \cdot 10^{-2} \cdot \beta-1,39 \cdot 10^{-4} \cdot \alpha \cdot \beta
\end{aligned}
$$

Разница в значениях параметров по результатам симуляций и рассчитанных по моделям (2)-(4) составила менее 1,1 \%, что указывает на адекватность полученных моделей.

Исходя из требований качества реза для введенных параметров, желаемыми значениями следует считать:

$$
k_{b}=0,5 ; \quad k_{e}=0,5 ; \quad k_{d} \rightarrow 1
$$

Совместное решение уравнений (2) и (3) при значениях коэффициентов $k_{b}$ и $k_{e}$ соответствующих (5), позволило определить рациональные значения углов конфигурации ножа, которые составили $\alpha=95,6^{\circ}$ и $\beta=10^{\circ}$. При этих значениях углов профилировки ножа ромбичность составила $k_{d}=1,05$, что удовлетворяет условию (5). На рис. 4 представлены графические зависимости между углами $\alpha$ и $\beta$, полученные на основании уравнений (2)-(4) с условиями (5), причем для уравнения (4) брали $k_{d}=1,05$. Как видно из рис. 4 , все три зависимости пересекаются в точке с координатами $\alpha=95,6^{\circ}$ и $\beta=10^{\circ}$.

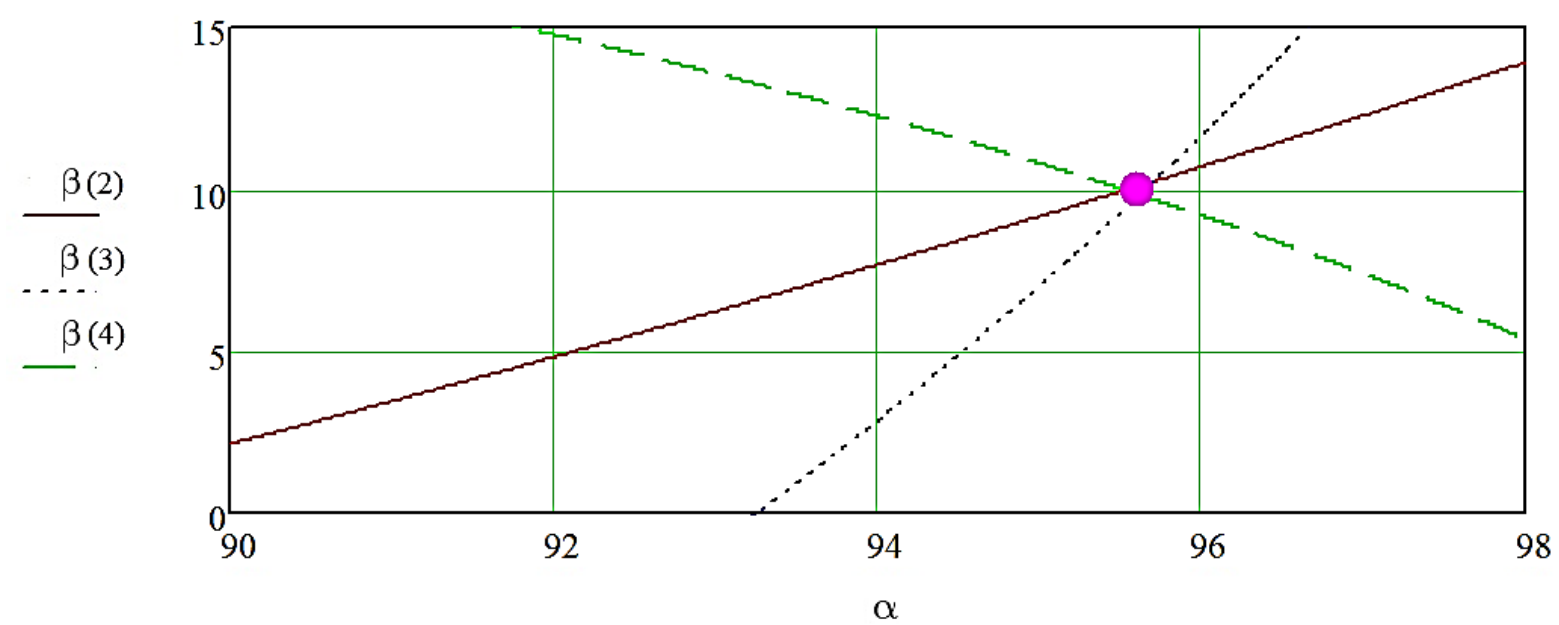

Рис. 4. Графические зависимости между углами $\alpha$ и $\beta$, полученные на основании уравнений (2)-(4) при $k_{b}=0,5, k_{e}=0,5$ и $k_{d}=1,05$

Для оценки правильности полученных значений углов профилировки ножа моделировали процесс разделения заготовки при данных величинах. Вид сбоку разделенных частей заготовки и профиль формы торцевой поверхности заготовки после порезки, полученные по результатам моделирования, представлены на рис. 5.

Анализ полученных результатов подтверждает высокую степень сходимости результатов моделирования МКЭ и расчетных показателей по уравнениям регрессии (2)-(4). Таким образом, можно утверждать, что полученный алгоритм расчета показателей качества процесса резки непрерывнолитой горячей квадратной заготовки фасонными ножами на угол позволяет определить рациональные значения углов профилировки ножей и обеспечить необходимые требования к качеству реза. 


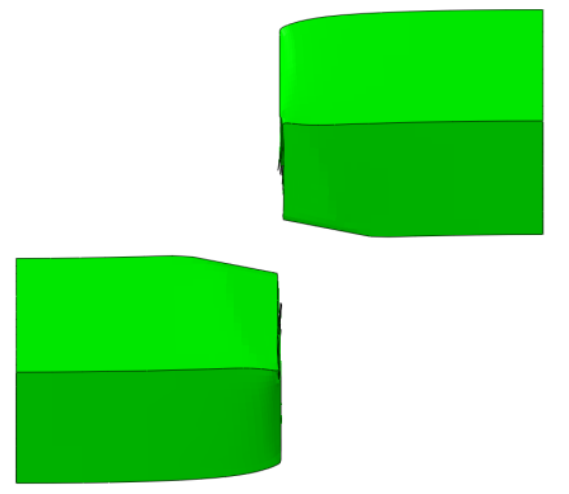

a

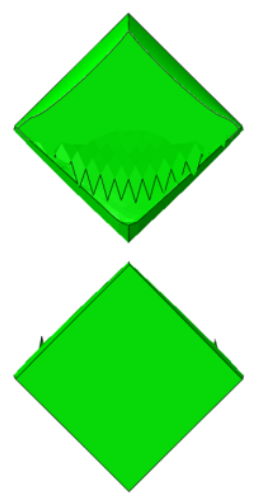

б

Рис. 5. Вид сбоку (а) разделенных частей заготовки и профиль формы (б) торцевой поверхности заготовки после порезки, полученные по результатам моделирования при $\alpha=95,6^{\circ}$ и $\beta=10^{\circ}$

\section{ВЫВОДЫ}

По результатам работы можно сделать следующие выводы:

- процесс разделения металла на ножницах следует считать более эффективным, поскольку он обладает безотходностью и имеет более высокую скорость резки, а также точность и качество реза в сравнении с другими способами;

- для повышения степени научной обоснованности при принятии технологических и конструктивных решений процессов резки на ножницах целесообразно применять математическое моделирование на базе метода конечных элементов;

- получены уравнения регрессии основных показателей качества при разделении непрерывнолитой горячей квадратной заготовки фасонными ножами на угол, которые позволяют обосновать рациональные значения углов профилировки ножей и обеспечить необходимые требования к качеству реза.

Результаты работы могут быть рекомендованы к использованию при принятии проектно-конструкторских и технологических решений в вопросах горячего разделения непрерывнолитой квадратной заготовки фасонными ножами на угол.

\section{СПИСОК ИСПОЛЬЗОВАННОЙ ЛИТЕРАТУРЫ}

1. Іванченко Ф. К. Розрахунок машин і механізмів прокатних цеехв : навч. посіб. / Ф. К. Іванченко, В. М. Гребеник, В. І. Ширяєв. - К. : Вищза шк., 1995. - 455 с. : іл.

2. Лукашин Н. Д. Конструкциия и расчет машин и агрегатов металлургических заводов: учебник для вузов / Н. Д. Лукашин, Л. С. Кохан, А. М. Якушев. - М. : ИКЦ «Академкнига», 2003. - 456 с. : ил.

3. Трусковский В. И. Развитие и совершенствование способов и механических схем резки сортового проката / В. И. Трусковский, Р. А. Закиров // Наука и технологии. Избр. тр. Российской школь. Серия «Технологии и машины обработки давлением». - М. : РАН, 2005. - С. 129-133.

4. Трусковский В. И. Ножницы для резки сортового проката и толстостенных труб / В. И. Трусковский, В. Г. Шеркунов // Металлург. - 2012. - № 11. - С. 63-66.

5. Прокат сортовий $і$ фасонний із сталі вуглецевої звичайної якості. Загальні технічні умови : ДСТУ 4484:2005 / ГОСТ 535-2005. - Чинний від 2005-11-25. - К. : Держспоживстандарт Украйни, 2005. - 14 с. (Держспоживстандарт Украӥни).

6. Прокат сортовий сталевий гарячекатаний квадратний. Сортамент : ДСТУ 4746:2007 / ГОСТ 2591-2006. Чинний від 2007-02-26. - К. : Держспоживстандарт Украӥни, 2007. - 6 с. - (Держспоживстандарт Украӥни).

7. ГОСТ 8559-75 Сталь калиброванная квадратная. Сортамент. - Введ. 1976-01-01. - М. : Госстандарт СССР, 1975. - 5 c. - (Государственный комитет СССР по управлению качеством продукиии и стандартам).

8. Металопродукиія. Методи вимірювання відхилів форми : ДСТУ 6026:2008 / ГОСТ 26877-2008. Чинний від 2013-01-01. - К. : Держспоживстандарт України, 2008. - 23 с. - (Держспоживстандарт України).

9. ГОСТ 21014-88. Прокат черных металлов. Термины и определения дефектов поверхности. - Введ. 1990-01-01. - М. : Госстандарт СССР, 1989. - 60 с. - (Государственный комитет СССР по управлению качеством продукиии и стандартам).

10. Боровик П. В. Новые подходы к математическому моделированию технологических процессов обработки давлением : монография / П. В. Боровик, Д. А. Усатюк. - Алчевск : ДонДТУ, 2011. - 299 с. 
11. Боровик П. В. 3D-модель процесса поперечного разделения на ножницах непрерывнолитых сортовых заготовок / П. В. Боровик, П. А. Петров // Сборник научных трудов ДонГТУ. - Алчевск, 2013. - Вып. 41. C. $151-155$.

12. Боровік П. В. Теоретичні дослідження процесів обробки металів тиском на основі методу скінчених елементів : навч. посіб. / П. В. Боровік. - Алчевськ : ДонДТУ, 2012. - 170 с.

13. Боровик П. В. Выбор метода расчета механических свойств при моделировании процесса горячей резки на ножницах / П. В. Боровик // Актуальные вопросы современной техники и технологии : сб. докладов IXй Международной научной конференциии (2. Липецฺк, 27 октября 2012 г.). / Отв. ред. А. В. Горбенко. - Липецฺк : Изд. изентр «Гравис», 2012. - С. 45-52

14. Львовский Е. Н. Статистические методы построения эмпирических формул : учеб. пособ. для вузов / Е. Н. Львовский. - 2-е изд., перераб. и доп. - М. : Высш. шк., 1988. - 239 с.

\section{REFERENCES}

1. Ivanchenko F. K. Rozrahunok mashin i mehanizmiv prokatnih cehiv : navch. posib. / F. K. Ivanchenko, V. M. Grebenik, V. I. Shirjacv. - K. : Vishha shk., 1995. - 455 s. : il.

2. Lukashin N. D. Konstrukcija i raschet mashin i agregatov metallurgicheskih zavodov: uchebnik dlja vu-zov / N. D. Lukashin, L. S. Kohan, A. M. Jakushev. - M. : IKC «Akademkniga», 2003. - 456 s. : il.

3. Truskovskij V. I. Razvitie i sovershenstvovanie sposobov i mehanicheskih shem rezki sortovogo prokata / V. I. Truskovskij, R. A. Zakirov // Nauka i tehnologii. Izbr. tr. Rossijskoj shkoly. Serija «Tehnologii i mashiny obrabotki davleniem». - M. : RAN, 2005. - S. 129-133.

4. Truskovskij V. I. Nozhnicy dlja rezki sortovogo prokata i tolstostennyh trub / V. I. Truskovskij, V. G Sherkunov // Metallurg. - 2012. - № 11. - S. 63-66.

5. Prokat sortovij i fasonnij iz stali vuglecevoï zvichajnoï jakosti. Zagal'ni tehnichni umovi : DSTU 4484:2005 / GOST 535-2005. - Chinnij vid 2005-11-25. - K. : Derzhspozhivstandart Ukraïni, 2005. - 14 s. - (Derzhspozhivstandart Ukraïni).

6. Prokat sortovij stalevij garjachekatanij kvadratnij. Sortament : DSTU 4746:2007 / GOST 2591-2006. Chinnij vid 2007-02-26. - K. : Derzhspozhivstandart Ukrä̈ni, 2007. - 6 s. - (Derzhspozhivstandart Ukraïni).

7. GOST 8559-75 Stal' kalibrovannaja kvadratnaja. Sortament. - Vved. 1976-01-01. - M. : Gosstandart SSSR, 1975. - 5 s. - (Gosudarstvennyj komitet SSSR po upravleniju kachestvom produkcii $i$ standartam).

8. Metaloprodukcija. Metodi vimirjuvannja vidhiliv formi : DSTU 6026:2008 / GOST 26877-2008. - Chinnij vid 2013-01-01. - K. : Derzhspozhivstandart Ukraïni, 2008. - 23 s. - (Derzhspozhivstandart Ukraïni).

9. GOST 21014-88. Prokat chernyh metallov. Terminy i opredelenija defektov poverhnosti. - Vved. 1990-01-01. - M. : Gosstandart SSSR, 1989. - 60 s. - (Gosudarstvennyj komitet SSSR po upravleniju kachestvom produkcii $i$ standartam).

10. Borovik P. V. Novye podhody $k$ matematicheskomu modelirovaniju tehnologicheskih processov ob-rabotki davleniem : monografija / P. V. Borovik, D. A. Usatjuk. - Alchevsk: DonDTU, 2011. - 299 s.

11. Borovik P. V. 3D-model' processa poperechnogo razdelenija na nozhnicah nepreryvnolityh sortovyh zagotovok/ P. V. Borovik, P. A. Petrov // Sbornik nauchnyh trudov DonGTU. - Alchevsk, 2013. - Vyp. 41. - S. 151-155.

12. Borovik P. V. Teoretichni doslidzhennja procesiv obrobki metaliv tiskom na osnovi metodu skinchenih elementiv: navch. posib. / P. V. Borovik. - Alchevs'k: DonDTU, 2012. - 170 s.

13. Borovik P. V. Vybor metoda rascheta mehanicheskih svojstv pri modelirovanii processa gorjachej rezki na nozhnicah / P. V. Borovik // Aktual'nye voprosy sovremennoj tehniki i tehnologii : sb. dokladov IX-j Mezhdunarodnoj nauchnoj konferencii (g. Lipeck, 27 oktjabrja 2012 g.). / Otv. red. A. V. Gorbenko. - Lipeck : Izd. centr «Gravis», 2012. S. $45-52$

14. L'vovskij E. N. Statisticheskie metody postroenija jempiricheskih formul : ucheb. posob. dlja vuzov / E. N. L'vovskij. - 2-e izd., pererab. i dop. - M. : Vyssh. shk., 1988. - 239 s.

Боровик П. В. - - канд. техн. наук ВНУ им. В. Даля.

ВНУ им. В. Даля - Восточноукраинский национальный университет имени Владимира Даля, г. Северодонецк.

E-mail: borovikpv@ukr.net 